International Journal of Engineering \& Technology, $7(1)(2018) 57-64$
SPC
International Journal of Engineering \& Technology
Website: www.sciencepubco.com/index.php/IJET
doi: $10.14419 /$ ijet. $v 7$ il. 8822
Research paper

\title{
Compact UWB microstrip antenna with quadruple band-notched characteristics for short distance wireless tele-communication applications
}

\author{
Kalyan Rayavaram ${ }^{1 *}$, K.T.V.Reddy ${ }^{2}$, Kesari Padma Priya ${ }^{3}$ \\ ${ }^{1}$ Department of Electronics and Communication Engineering, JNTUniversityAnantapur, Anantapuramu, Andhra Pradesh, India \\ ${ }^{2}$ IETE $H Q$, New Delhi, India \\ ${ }^{3}$ Department of Electronics and Communication Engineering, UCEK, JNTUniversityKakinada, Kakinada, Andhra Pradesh, India \\ *Corresponding author E-mail: r.kalyanreddy@gmail.com
}

\begin{abstract}
In this paper, the design and simulation of a compact ultra-wide band (UWB) microstrip antenna with quadruple band-notched characteristics for short-distance wireless telecommunication applications were explored. The design process of the antenna is carried on FR4 substrate with dielectric constant 4.4 , loss tangent 0.02 , thickness of $0.8 \mathrm{~mm}$ and the size of the proposed antenna are $30 \times 20 \mathrm{~mm}^{2}$. The rectangular monopole antenna endures a rectangular radiating patch with chamfered bevel slots on the top side, and a defective ground planed on the bottom side of the substrate. To realize single, dual, triple and quadruple band notch characteristics, slot- 1 is created on the patch to achieve first notch at $3.5 \mathrm{GHz}$, which eliminates WIMAX signal, slot-2 is created on the patch to achieve second notch at 4.6 $\mathrm{GHz}$, which eliminates INSAT signal, slot-3 is created on the patch to achieve third notch at $5.5 \mathrm{GHz}$, which eliminates WLAN signal and also fourth notch is created at $9.5 \mathrm{GHz}$ which eliminates X-band frequency with slot-1 outer length. The proposed antenna is well miniaturized and can be easily integrated with any compact devices. The simulated result shows that proposed antenna gain a good range of UWB from (2.6 GHz to $13.4 \mathrm{GHz})$.
\end{abstract}

Keywords: Band Notched Characteristics; Chamfered Bevel Slots; Defective Ground Plane; Monopole Antenna; Ultra-Wide Band.

\section{Introduction}

In wireless communication technology Ultra-Wideband (UWB) is a widely admired and attractive technique used for short-range communication applications. From the past few years, UWB have to become the highlight of wireless communication due to advantages of less power spectral density, maximized data rate, low power utilization and many others. Allocation of bandwidth ranging from 3.1 to $10.6 \mathrm{GHz}$ was done by the Federal Communication Commission (FCC) In February 2002 to be used for shortrange communication purposes, by far the demand for UWB increasing rapidly [1]. A lot of research on UWB system brought some challenges, including their impedance matching, compact size, low manufacturing cost, etc., which are introduced while designing an antenna for UWB applications. The operating frequency of UWB allocated by FCC includes more narrowband wireless standards that have been allocated to share some part of this spectrum. These include INSAT $4.6 \mathrm{GHz}$, wireless local area network (WLAN) services $5.5 \mathrm{GHz}$ etc. which interfere with the UWB system. So somewhere its needed an antenna with band notched property that can diminish the unwanted interferences from this coexisting wireless system rather than by using an additional band stop filter. There are various methods, which are helpful for introducing a notch in UWB antenna. The most commonly used technique is by adding different slots on the radiating material or in the ground plane or also on the feed line. Different shapes are used like V shaped slot is used on the patch to create band notch characteristics [2]. As reported, a T-shaped slot in the radiat- ing patch provides strong notch band rejections up to VSWR $=26$, which is tuneable over a wide frequency range from $3.55 \mathrm{GHz}$ to $6.80 \mathrm{GHz}$ [3], A H-shaped slot is used in the elliptical open ended microstrip feed line to achieve band notched characteristics. The band rejection characteristics can be controlled by varying the dimensions of $\mathrm{H}$ slot [4], U shaped filter is used on a UWB planer monopole antenna to eliminate WLAN frequency [5]. A band notched frequency is created by placing a C-shaped slot on the elliptic radiating patch. The slot length contributes to both the notch bandwidth and center frequency of notch while the slot width contributes mainly to the bandwidth of notch [6], Two stop bands are created by embedding a T-shaped stub in the square slot of the radiation patch and a pair of U-shaped parasitic strips beside the feed line on the substrate [7], two short circuit folded stepped impedance resonators are used two achieve dual band notched characteristics. the folded SIRs are inserted for stopping unwanted frequency bands [8], a microstrip open-loop resonator is used on the ground plane to generate frequency band notch [9]; a modified complementary split-ring resonator (CSRR) is placed inside the inner patch to obtain band rejection characteristics [10], a pair of bended dual- L-shape branches are attached to the slotted ground to achieve dual band notched characteristics [11], Two stop bands are obtained by placing four $\mathrm{u}$-shaped slots with a different dimension on the radiating patch, and the stop band bandwidth can be controlled by adjusting the three u-slots dimension [12], Two notched frequency bands are created by a pair of C-shaped slots and a U-shaped slot placed on the radiating patch. Good gain and radiation patterns in the operating frequency have been noted [13], by adding a meandering slot on the radiation patch and, with add- 
ing a pair of symmetrical C-shape strips to the feed-line dual band notched characteristics are achieved [14]. Two compacts, printed, ultra wide band (UWB) monopole antennas with the tri-band notched characteristics are reported. The notched filters are achieved by introducing printed, electrically small, capacitive loaded loop (CLL) resonators [17]. A very compact coplanar waveguide (CPW)-fed ultra wide band (UWB) printed monopole antenna (PMA) with triple band-notched characteristics is presented. The antenna uses three open-ended quarter-wavelength slots to create triple band-notched characteristics [18]. a novel low-profile micros trip-fed compact triple band-notched ultra wide band (UWB) antenna is proposed. Notch bands around the 3.3-3.8-GHz WiMAX and 5.15-5.85-GHzWLANfrequencies are obtained by etching out two elliptic single complementary split-ring resonators (ESCSRRs) of different dimensions from the radiating patch of the antenna. Furthermore, by placing two rectangular split-ring resonators near the feedline-patch line-patch junction of the antenna, rejection for the $7.9-8.4-\mathrm{GHz} \mathrm{X}$-band frequencies are achieved [19]. Simple and compact circular ultra-wide band (UWB) planar monopole antenna with dual band-notched characteristics is presented. By inserting a pair of two slots in the ground plane as well as adding a pair of arc-shaped parasitic strips around the radiating element, two notched frequency bands in the WiMAX/WLAN are achieved [20]. However, the above design has larger size of the antenna or limited band notch performance. This paper presents a novel design of UWB monopole micros trip antenna with slots on the radiating patch. The proposed antenna covers the full range of UWB and also its capable of rejecting frequencies like WIMAX, INSAT signal, WLAN band and $\mathrm{X}$ band frequency. This approach has acceptable band notch perfor- mance without increasing size and complexity of antenna and how it is achieved is discussed in the following section.

\section{Antenna design}

\subsection{Design of UWB antenna without notched bands}

First, the basic antenna covering the entire band width of UWB frequency range without any band notched characteristics is discussed. In this section, the variations in patch and ground plane are discussed to achieve UWB. The feed line and the radiating patch are attached to each other so these are printed at the top of the substrate and on the bottom side ground, plane is printed. The design procedure of radiating patch to achieve UWB with a defective ground plane of size $20 \times 13 \mathrm{~mm}^{2}$ has 3 cases as shown in fig. 1 . In case 1 the design starts with a rectangular monopole antenna, a $10 \mathrm{~dB}$ return loss bandwidth is obtained by changing the width between the patch and ground plane since for the rectangular monopole the ground plane serves as an impedance matching circuit. In case 2 symmetrical bevel slots are etched on the lower edges of the patch, etching of slots looks as steps on the lower side of the monopole radiating patch [16]. This slot with dimensions of W2 and L2 plays a significant role in achieving wider band width. In case 3 the patch was chamfered at the bottom edges of radiating patch above the bevel slots, this is to create the good impedance matching for the patch and the ground plane. Chamfering the edges (case 3) of slots and increasing the width of slots (case 2) support the traveling wave from lower frequency to higher frequencies as shown in fig. 1. It can also be mentioned that by decreasing the width $\mathrm{W} 1$ as shown in fig. 2. The VSWR goes below 2 .

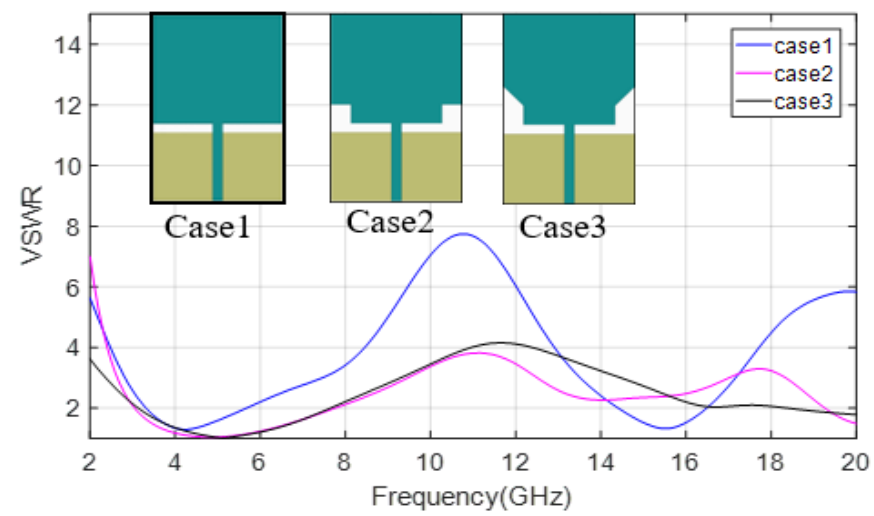

Fig. 1: Procedure Design of Ultra-Wide Band Antenna.

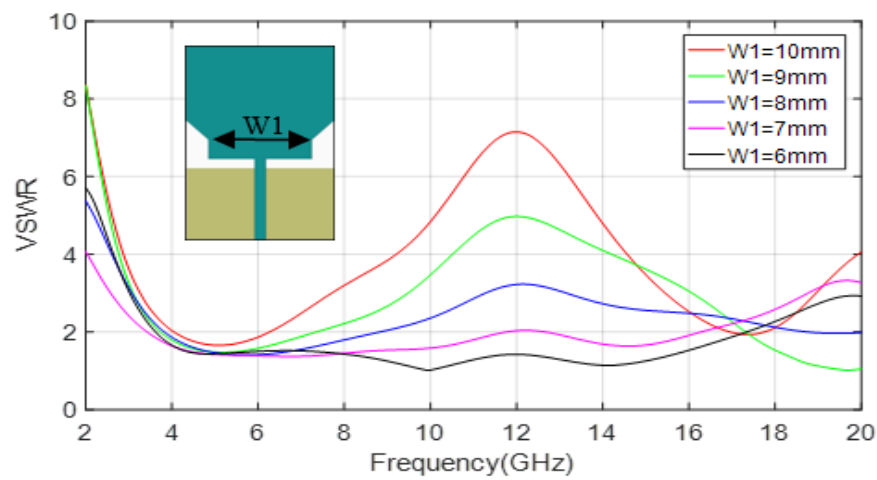

Fig. 2: VSWR Variation with Variation in W1.

\subsection{Design of UWB antenna with band notches}

The design of proposed antenna with quadruple notched band characteristics for UWB applications is shown in figure 3. Initially in the previous section the designed antenna covers the full range of UWB with the microstrip feed line width as $1.5 \mathrm{~mm}$ to achieve
$50 \Omega$ character impedance. In the presented design slots on the radiating patch are introduced (figure 4.) to achieve notches at $3.5 \mathrm{GHz}$ (WIMAX), $4.6 \mathrm{GHz}$ (INSAT signal), $5.5 \mathrm{GHz}$ (WLAN signal) and $9.5 \mathrm{GHz}$ (X-band) frequencies. The simulation process of proposed antenna was done on HFSS 13 software. Table 1 shows the optimized dimensions of the antenna. 
(A)

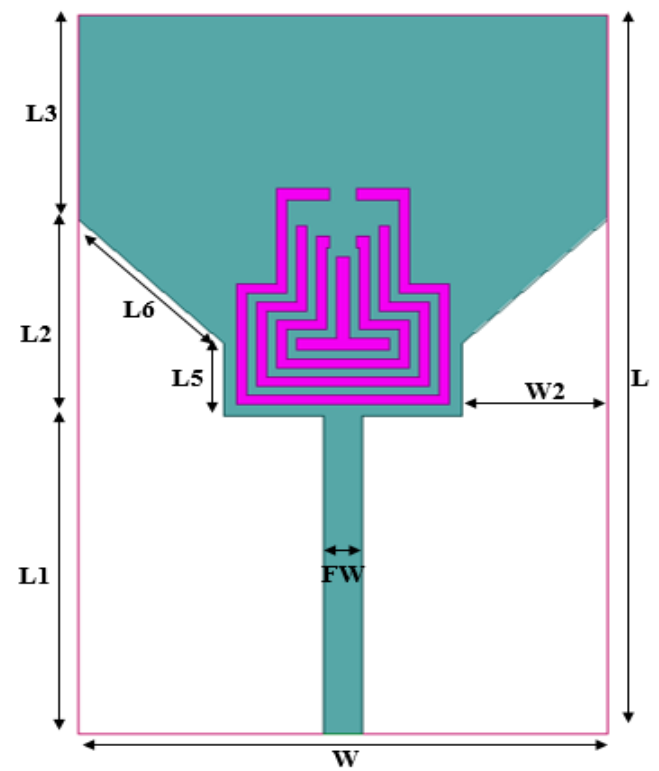

(B)

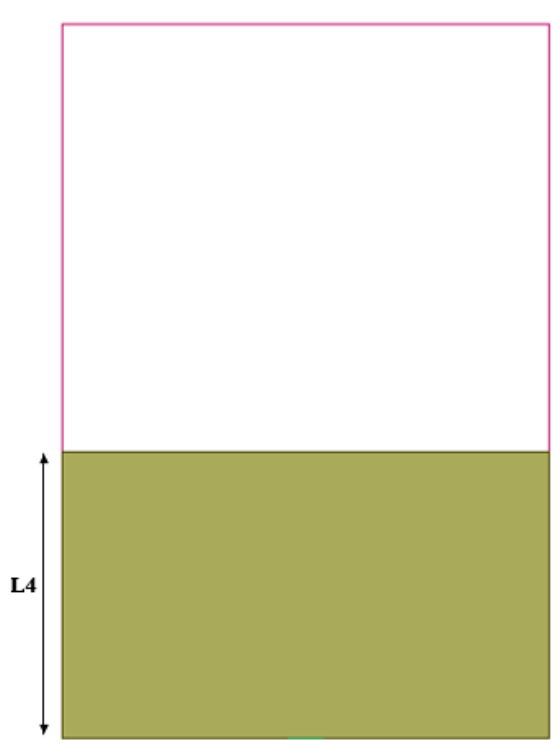

(C)

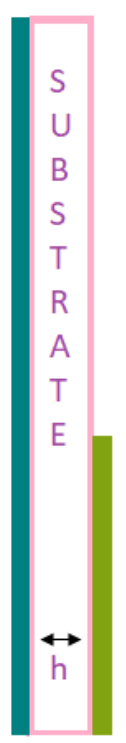

Fig. 3: Proposed Ultra-Wide Band Antenna with Quadruple Notched Bands (A) Top View (B) Bottom View (C) Side View.

(A)

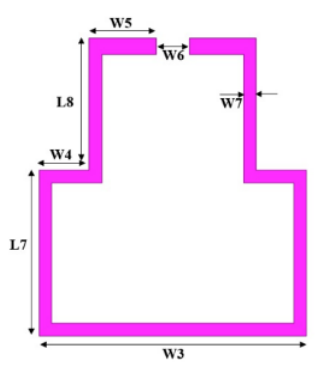

(B)

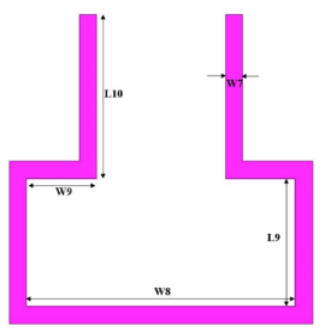

(C)

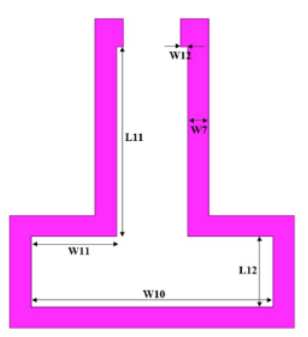

(D)

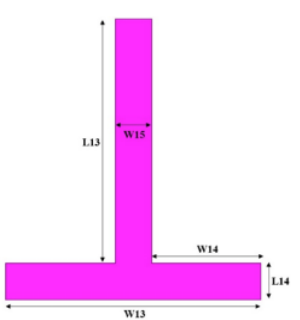

(E)

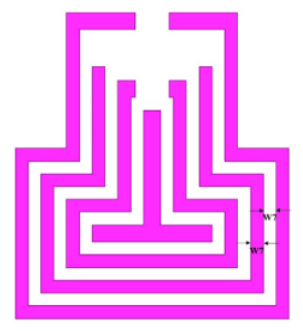

Fig. 4: Slots of the Proposed Antenna to Create Notched Bands (A) Slot-1 (B) Slot-2 (C) Slot-3 (D) Slot-4 (E) Combined View.

Table 1: Optimized Dimensions of the Proposed UWB Antenna with Quadruple Notched Bands

\begin{tabular}{llllllll}
\hline Parameter & Length $(\mathrm{mm})$ & Parameter & Length $(\mathrm{mm})$ & Parameter & Length $(\mathrm{mm})$ & Parameter & Length $(\mathrm{mm})$ \\
\hline L & 30 & L8 & 4 & W & 20 & W8 & 5.75 \\
L1 & 13.3 & L9 & 2.75 & FW & 1.5 & W9 & 1.5 \\
L2 & 9.5 & L10 & 4 & W2 & 5.5 & W10 & 4.25 \\
L3 & 8.5 & L11 & 4 & W3 & 8 & W11 & 1.5 \\
L4 & 12 & L12 & 1.25 & W4 & 1.5 & W12 & 0.125 \\
L5 & 3 & L13 & 4 & W5 & 2 & W13 & 3.5 \\
L6 & 8.92 & L14 & 0.5 & W6 & 1 & W14 & 1.5 \\
L7 & 5 & h & 0.8 & W7 & 0.375 & W15 & 0.5 \\
\hline
\end{tabular}

\subsection{Slot dimensions}

The total length of the slots is calculated by the following formulae at centre frequency of notched bands

$\mathrm{L}_{\text {slot }}=\frac{\mathrm{C}}{2 \mathrm{f}_{\mathrm{i}} \sqrt{\varepsilon_{\text {eff }}}}$

$\varepsilon_{\mathrm{eff}}=\frac{\varepsilon_{\mathrm{r}}+1}{2}$

Where $\mathrm{c}$ denotes the velocity of light in free space, $\varepsilon_{\mathrm{r}}$ is the substrate dielectric constant, $\varepsilon_{\text {eff }}$ is the effective dielectric constant and $f_{i}(i=$ slot $)$ is the center frequency of the notched bands. For slot- 1 of WIMAX signal notch band whose center frequency of $3.5 \mathrm{GHz}$ the slot lengths theoretically calculated value is $\mathrm{L}_{\text {Theoretical }}=26.13 \mathrm{~mm}$ and practically calculated value is $L_{\text {Practical }}=26 \mathrm{~mm}$. For slot -2 of INSAT signal notch band whose center frequency of $4.6 \mathrm{GHz}$ the slot lengths theoretically calculated value is $L_{\text {Theoretical }}=19.89 \mathrm{~mm}$ and practically calculated value is $L_{\text {Practical }}=20 \mathrm{~mm}$. For slot -3 of WLAN notch band whose center frequency is $5.5 \mathrm{GHz}$ the slot lengths theoretically calculated value is $\mathrm{L}_{\text {Theoretical }}=16.6 \mathrm{~mm}$ and practically calculated value is $\mathrm{L}_{\text {Practical }}=15.87 \mathrm{~mm}$. For X-band signal notch whose center frequency of $9.5 \mathrm{GHz}$ the slot lengths theoretically calculated value is $\mathrm{L}_{\text {Theoretical }}=9.62 \mathrm{~mm}$ and practically calculated value is $\mathrm{L}_{\text {Practical }}=9 \mathrm{~mm}$. Table 2 shows the comparison between theoretical and practical values of slot lengths, there is good agreement between the theoretical and practical values with a minimum logical error.

Table 2: Comparison of Theoretical and Practical Values of Slot Lengths

Slot Notching Fre- $\quad$ Calculated length using formulae (1) in $\mathrm{mm} \quad$ Calculated length using parametric study in mm Logical




\begin{tabular}{lllll}
\hline Slot 1 inner & $3.5 \mathrm{GHz}$ & 26.13 & $26(\mathrm{~W} 3+\mathrm{L} 7 * 2+\mathrm{L} 8 * 2)$ & 0.13 \\
Slot 2 & $4.6 \mathrm{GHz}$ & 19.89 & 16.60 & $20(\mathrm{~W} 8+\mathrm{L} 9 * 2+\mathrm{L} 10 * 2)$ \\
Slot 3 & $5.5 \mathrm{GHz}$ & 09.62 & $15.87(\mathrm{~W} 10+\mathrm{L} 11 * 2+\mathrm{L} 12 * 2)$ & 0.11 \\
Slot 1 outer & $9.5 \mathrm{GHz}$ & $9(\mathrm{~W}-\mathrm{W} 2 * 2)$ & 0.62 \\
\hline
\end{tabular}

(A) Antenna 1

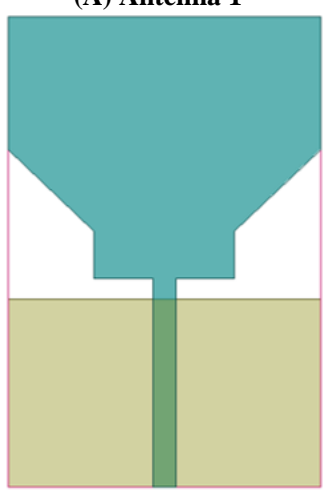

(B) Antenna 2

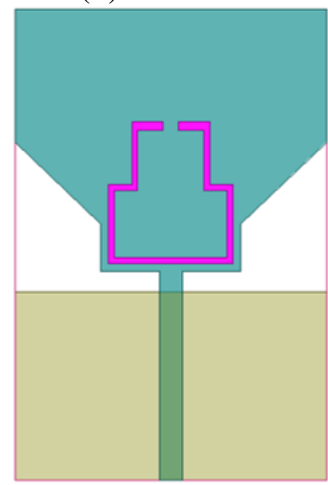

(C) Antenna 3

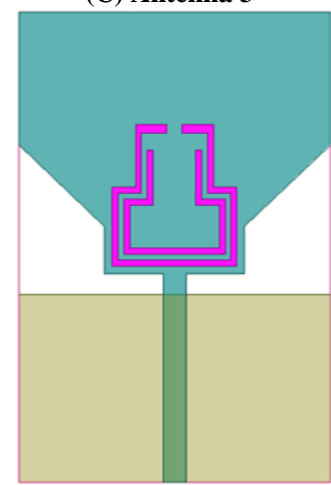

(D) Antenna 4

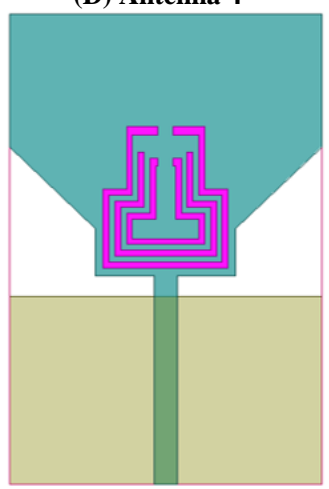

(E) Antenna 5 (Proposed)

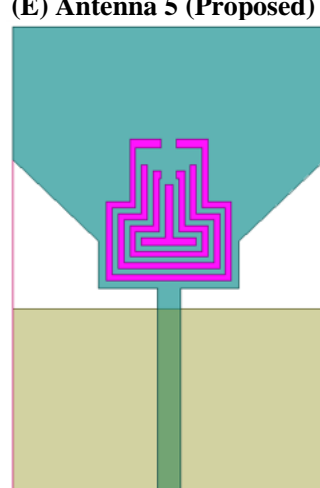

Fig. 5: Design Flow of Slots on Ultra-Wide Band Antenna (A) Antenna without Slots (B) Antenna with Slot-1 for 3.5 GHZ Notched Band (C) Antenna with Slot-1 and Slot-2 for 3.5 GHZ and 4.6 GHZ Notched Bands (D) Antenna with Slot-1, Slot-2 and Slot-3 for 3.5 GHZ, 4.6 GHZ and 5.5 GHZ Notched Bands (E) Antenna with Slot-1, Slot-2, Slot-3 and Slot-4 for 3.5 GHZ, 4.6 GHZ, 5.5 GHZ and 9.5 GHZ Notched Bands (Proposed Antenna).
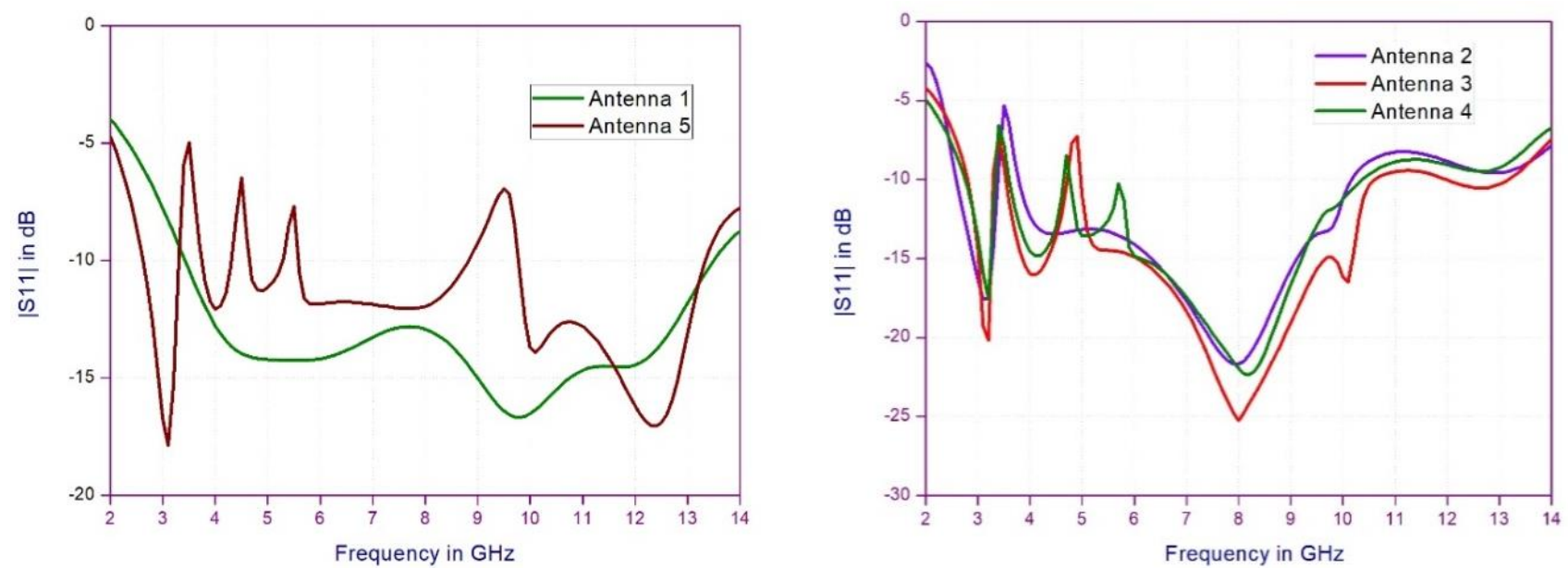

Fig. 6: The Simulated Return Loss of Antenna 1, Antenna 2, Antenna 3, Antenna 4 and Antenna 5.

\section{Parametric study of the slots at rejected frequencies}

The proposed antenna performance with different slots is characterised by Full-wave electromagnetic simulations which were carried out by Ansoft's high frequency structure simulator (HFSS) In order to reduce the interference with the WIMAX, INSAT, WLAN and $\mathrm{X}$ band frequencies the parametric study for different slots is carried out. Here the slot creates the capacitance and the capacitance depends on the length of the slot. Placing such type of slots near to the feeding edges of the patch a frequency filter is formed which characterise notched bands.

\subsection{The WIMAX rejected frequency}

Figure 7 shows the effect of length (W 3) of slot-1 dimensions. As observed the notch frequency is shifted from $4 \mathrm{GHz}$ to $3.5 \mathrm{GHz}$ when the length of slot- 1 is increased from $6 \mathrm{~mm}$ to $8 \mathrm{~mm}$.

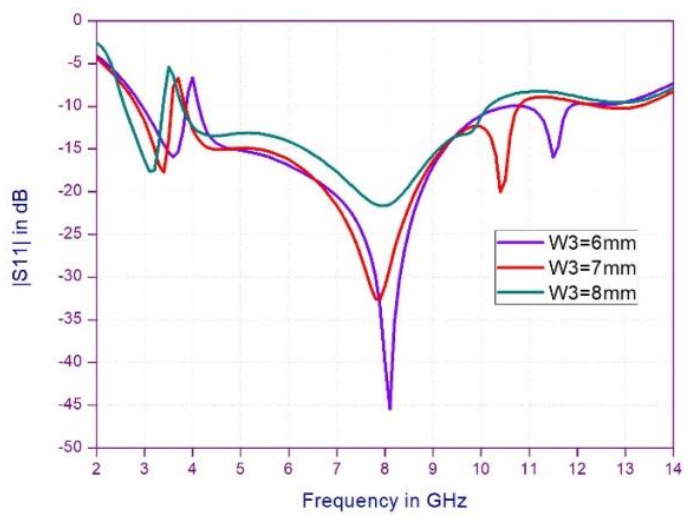

Fig. 7: S 11 Parameters for Slot-1 Variation in Length W 3.

Figure 8 shows the effect of length (W 7) of slot- 1 dimensions. As observed the notch frequency is varied from $3.2 \mathrm{GHz}$ to $3.7 \mathrm{GHz}$ when the length of slot- 1 is varied from $0.25 \mathrm{~mm}$ to $0.5 \mathrm{~mm}$. Here the length is taken as $0.375 \mathrm{~mm}$ to reject $3.5 \mathrm{GHz}$ Notched Band. 


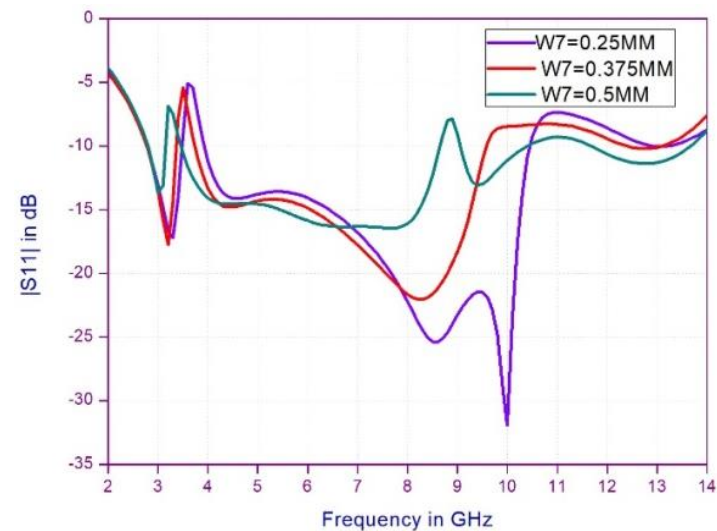

Fig. 8: S 11 Parameters for Slot-1 Variation in Length W 7.

Figure 9 shows the effect of length (L 7) of slot-1 dimensions. As observed the notch frequency is shifted from $3.9 \mathrm{GHz}$ to $3.5 \mathrm{GHz}$ when the length of slot- 1 is increased from $3 \mathrm{~mm}$ to $5 \mathrm{~mm}$.

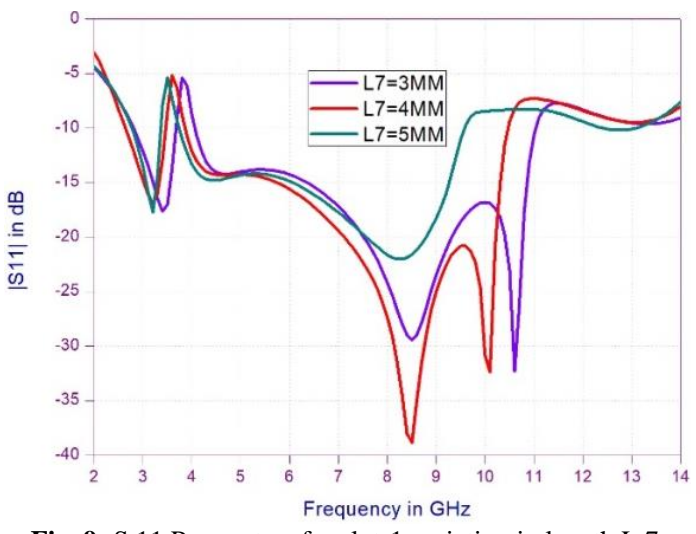

Fig. 9: S 11 Parameters for slot-1 variation in length $L 7$.

Figure 10 shows the effect of length (L 8) of slot-1 dimensions. As observed the notch frequency is shifted from $3.8 \mathrm{GHz}$ to $3.5 \mathrm{GHz}$ when the length of slot- 1 is increased from $2 \mathrm{~mm}$ to $4 \mathrm{~mm}$.

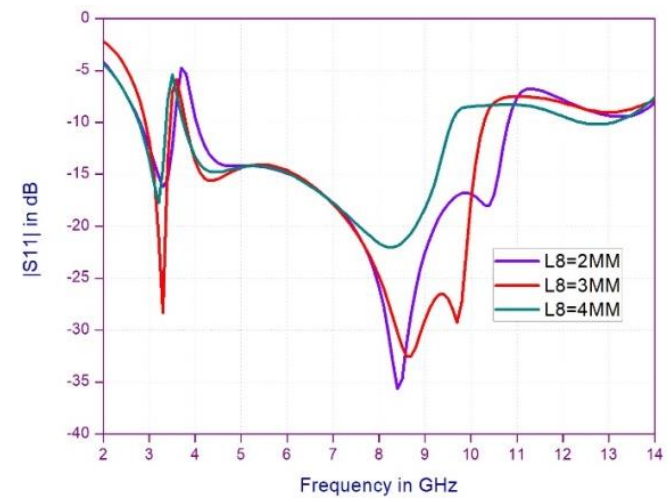

Fig. 10: S 11 Parameters for Slot-1 Variation in Length L 8 .

\subsection{The INSAT signal rejected frequency}

Figure 11 shows the effect of length (L 10) of slot-2 dimensions. As observed the notch frequency is shifted from $5 \mathrm{GHz}$ to 4.6 $\mathrm{GHz}$ when the length of slot- 2 is increased from $2 \mathrm{~mm}$ to $4 \mathrm{~mm}$.

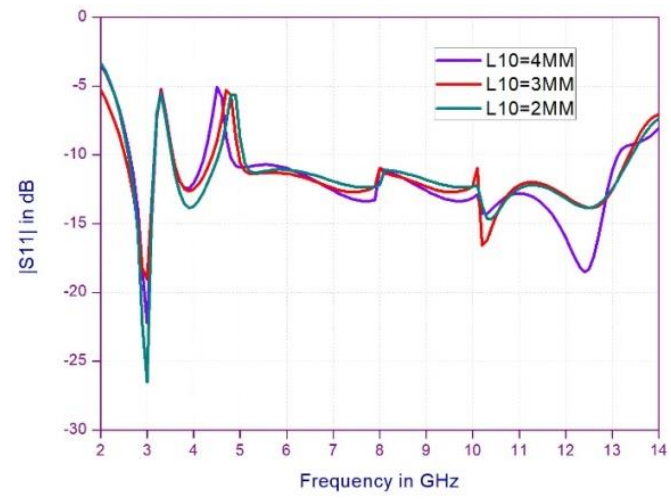

Fig. 11: S 11 Parameters for slot-2 variation in length $L 10$

\subsection{The WLAN rejected frequency}

Figure 12 shows the effect of length (W 12) of slot-3 dimensions. As observed the notch frequency is varied from $5.2 \mathrm{GHz}$ to 5.5 $\mathrm{GHz}$ when the length of slot-3 is decreased from $0.325 \mathrm{~mm}$ to $0.125 \mathrm{~mm}$. Here the length is taken as $0.125 \mathrm{~mm}$ to reject $5.5 \mathrm{GHz}$ Notched Band.

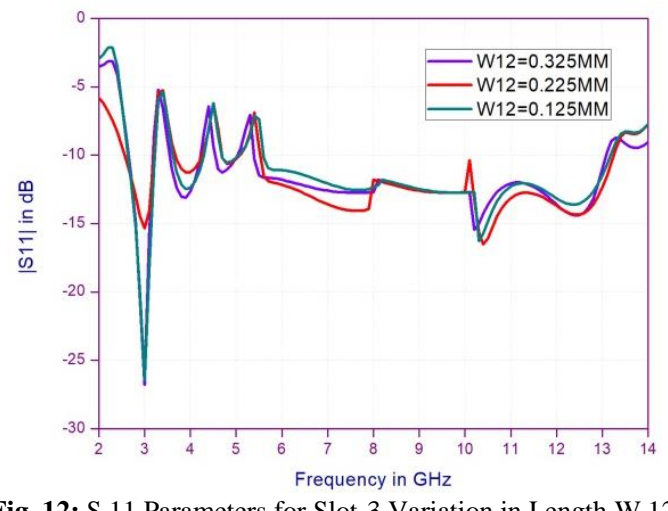

Fig. 12: S 11 Parameters for Slot-3 Variation in Length W 12.

\subsection{The $X-B a n d$ rejected frequency}

Figure 13 shows the effect of length (W 3) of slot-1 dimensions. As observed the notch frequency is shifted from $10.2 \mathrm{GHz}$ to 9.5 $\mathrm{GHz}$ when the length of slot-1 is increased from $6 \mathrm{~mm}$ to $8 \mathrm{~mm}$ also the reflection coefficient is varied from $-8 \mathrm{~dB}$ to $-4 \mathrm{~dB}$.

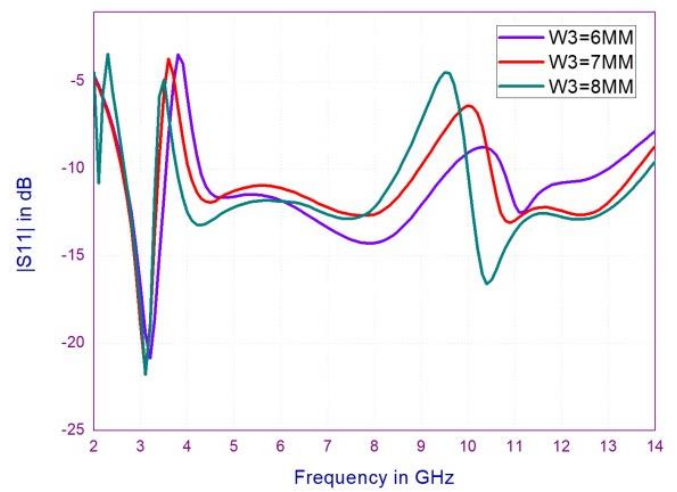

Fig. 13: S 11 Parameters for Slot-1 Variation in Length W 3.

\section{Results and discussion}

\subsection{S 11 vs frequency}

Figure 14 shows the S 11 parameters of the proposed UWB antenna with quadruple notch bands. As shown the antenna have the $S$ 11 parameter $<-10 \mathrm{~dB}$ for entire UWB frequency except at WIMAX, INSAT, WLAN and X band frequencies, this clearly indi- 
cate that at these frequencies where have the $\mathrm{S} 11$ parameter $>-10$ $\mathrm{dB}$ are exempted from the UWB range. Sharp notches are created by using these slots on the antenna.

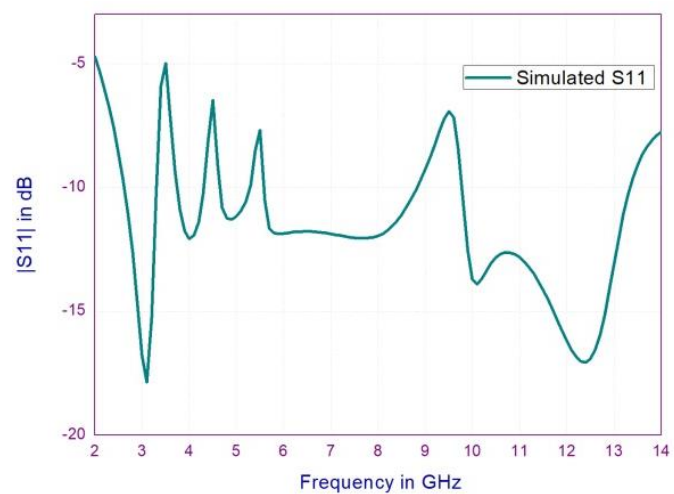

Fig. 14: S 11 Parameters of Proposed UWB Antenna with Quadruple Notch Bands

\subsection{VSWR vs frequency}

Figure 15 shows the VSWR of the proposed UWB antenna with quadruple notch bands. As shown the antenna have VSWR below 2 for entire UWB frequency except at WIMAX, INSAT, WLAN and $\mathrm{X}$ band frequencies, this clearly indicate that at these frequencies where VSWR is above 2 are exempted from the UWB range. Sharp notches are created by using these slots on the antenna.

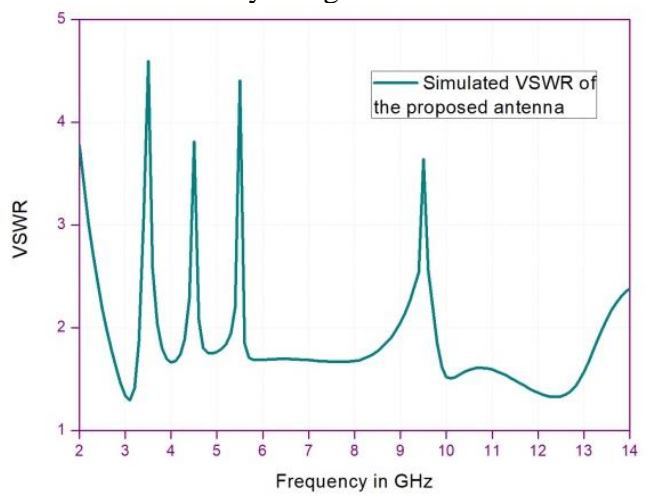

(A)

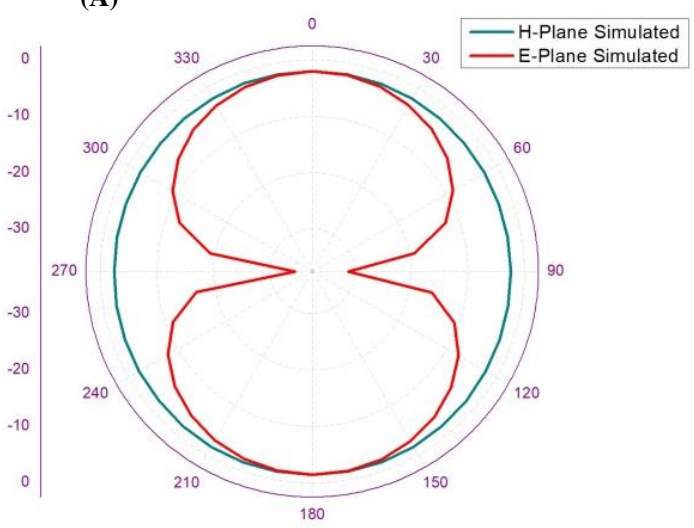

(C)
Fig. 15: VSWR of the Proposed UWB Antenna with Quadruple Notch Bands.

\subsection{Gain vs frequency}

Figure 16 shows the Gain of the proposed UWB antenna with quadruple notch bands.

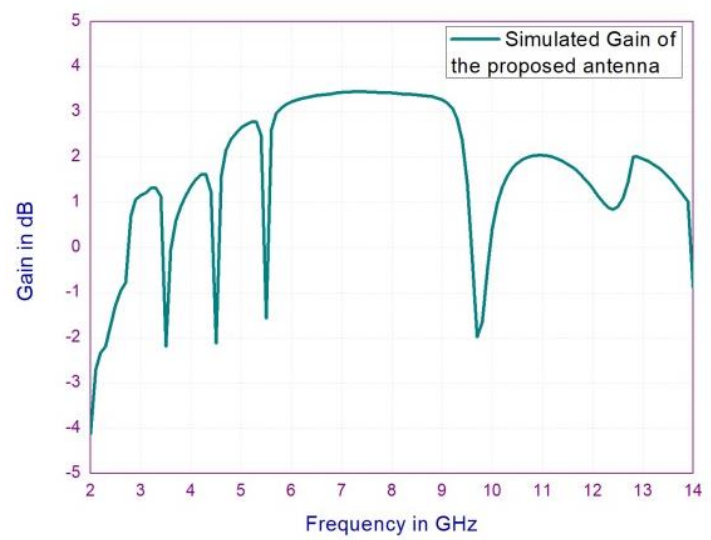

Fig. 16: Gain of the Proposed UWB Antenna with Quadruple Notch Bands.

\subsection{Radiation pattern}

Figure 17 shows the radiation pattern of the proposed UWB antenna for E-Plane (x-y plane) and H-Plane (y-z plane) at $3 \mathrm{GHz}$, $5 \mathrm{GHz}, 7 \mathrm{GHz}$ and $9 \mathrm{GHz}$. The antenna has isotropic radiation pattern in H-Plane and Omnidirectional radiation pattern in E-Plane also it is clear that in the lower frequencies the prefect omnidirectional pattern is observed and at the higher frequencies the radiation pattern is scattered

(B)

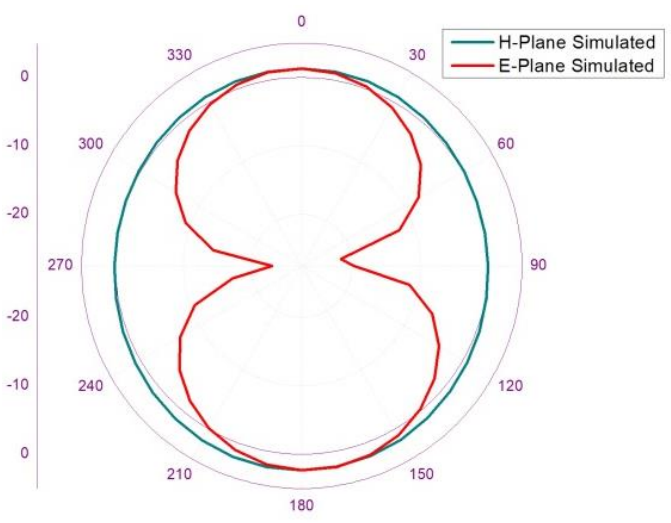

(D) 


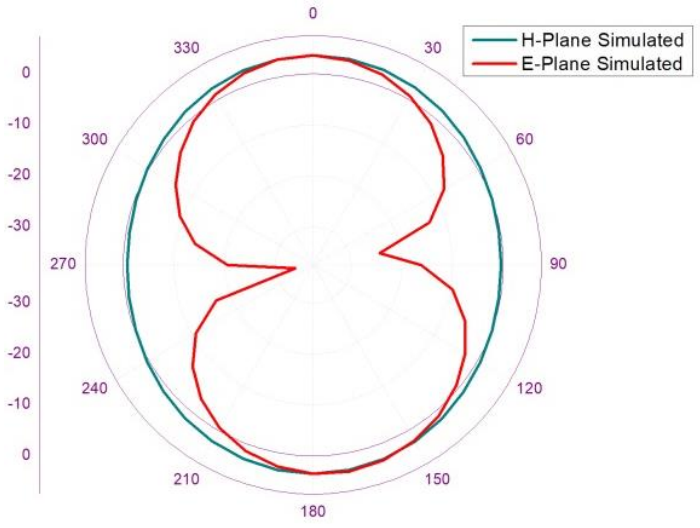

Fig. 17: Two Dimensional Radiation Pattern of the Proposed UWB Antenna (A) 3 GHZ (B) 5 GHZ (C) 7 GHZ (D) 9 GHZ.

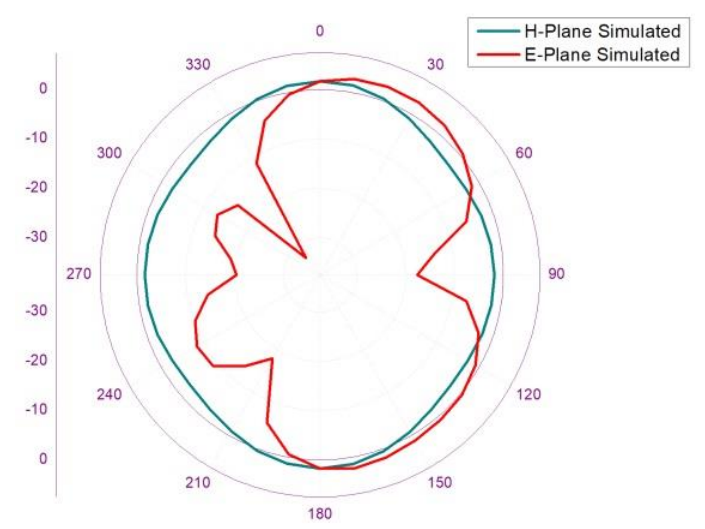

notch frequency at $5.5 \mathrm{GHz}$ the current is concentrated at slot-3 inner length as shown in fig.18(C), For the fourth notch frequency at $9.5 \mathrm{GHz}$ the current is concentrated at slot-1 outer length as shown in fig.18(D).

Table 3 shows the comparison between reported antennas with the proposed antenna. Compared to reported antennas proposed antenna has a better bandwidth, compact size, four notched bands.

For the second notch frequency at $4.6 \mathrm{GHz}$ the current is concentrated at slot-2 inner length as shown in fig.18(B), For the third

(B)

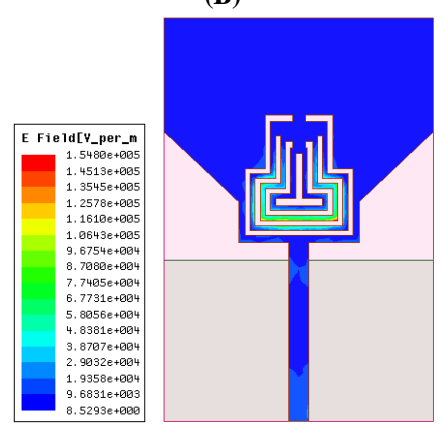

(D)

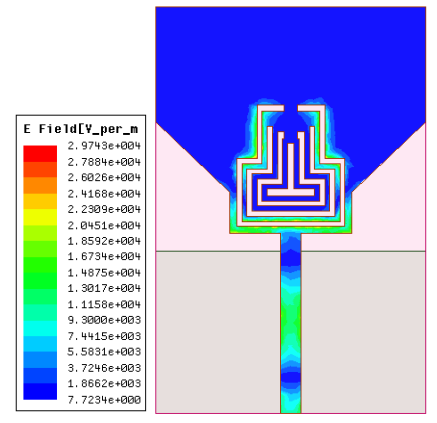

Fig. 18: Surface Current Distribution of The Proposed UWB Antenna At Notched Frequencies (a) 3.5 GHZ (b) 4.6 GHZ (c) 5.5 GHZ (d) 9.5 GHZ.

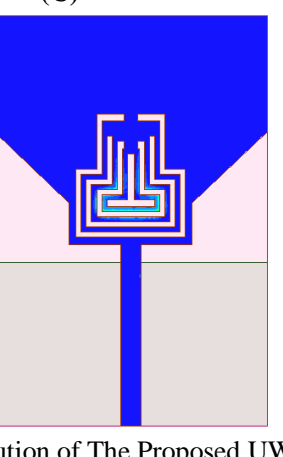

Table 3: Comparison of Proposed Antenna with Reported Antennas

\begin{tabular}{|c|c|c|c|c|c|c|}
\hline & Proposed work & Ref.[11] & Ref.[12] & Ref.[13] & Ref.[14] & Ref.[15] \\
\hline Dielectric constant & 4.4 & 4.4 & 4.4 & 4.4 & 4.4 & 4.4 \\
\hline Substrate size in $\mathrm{mm}$ & $30 * 20$ & $40 * 30$ & $37 * 34$ & $32 * 28$ & $30 * 24$ & $42 * 24$ \\
\hline Thickness in mm & 0.8 & 1.2 & 1 & 1.6 & 1.2 & 1.6 \\
\hline First notch band in $\mathrm{GHz}$ & 3.5 & 3.5 & $3.3-3.8$ & $3.24-3.78$ & 3.5 & $2.3-2.5$ \\
\hline Second notch band in $\mathrm{GHz}$ & 4.6 & 5.5 & $5.1-5.9$ & $5.13-6.32$ & 5.5 & - \\
\hline Third notch band in $\mathrm{GHz}$ & 5.5 & - & - & - & - & - \\
\hline Fourth notch band in $\mathrm{GHz}$ & 9.5 & - & - & - & - & - \\
\hline
\end{tabular}




\section{Conclusion}

This paper presents a compact ultra-wide band (UWB) microstrip antenna with quadruple band-notched characteristics, which covers the frequency range from 2.6 to $13.4 \mathrm{GHz}$. By introducing slot- 1 on the patch first notch at $3.5 \mathrm{GHz}$ is achieved, which eliminates WIMAX signal. Slot-2 is created on the patch to achieve second notch at $4.6 \mathrm{GHz}$, which eliminates INSAT signal, slot- 3 is created on the patch to achieve third notch at $5.5 \mathrm{GHz}$, which eliminates WLAN signal and also fourth notch is created at 9.5 $\mathrm{GHz}$ which eliminates $\mathrm{X}$ band frequency with slot-1 outer length. The band width of these filters can be adjusted by varying the dimensions of the slots. The designed antenna shows a maximum gain of $3.5 \mathrm{~dB}$ at $7.5 \mathrm{GHz}$. The proposed antenna is simple, compact, and gives excellent performance so these antennas are used in various UWB systems for short-distance wireless telecommunication applications.

\section{References}

[1] Federal communications commissions, Washington, DC, USA, Federal Communications Commission revision of Part 15 of the commission's rules regarding ultra-wideband transmission system from 3.1 to $10.6 \mathrm{GHz}, 2002$.

[2] R. Kalyan, K. T. V. Reddy, and K. Padma Priya. "compact band notch ultra-wide band microstrip antenna for short distance wireless applications", International Conference on Inventive Communication and Computational Technologies, 10-11 March 2017, Coimbatore, India, https://doi.org/10.1109/ICICCT.2017.7975161.

[3] Abbas, Syed Muzahir, Yogesh Ranga, Anand K. Verma, and Karu P. Esselle. "A simple ultra-wideband printed monopole antenna with high band rejection and wide radiation patterns", IEEE Transaction on Antennas and Propagation, 2014.

[4] A. A. Kalteh. "Design of a novel UWB Band-Notched Microstrip slot antenna", 2009 5th international conference on wireless communications networking and mobile computing 09/2009. https://doi.org/10.1109/WICOM.2009.5301568.

[5] Y. J. Cho, K. H. Kim, D. H. Choi, S. S. Lee, and S. O. Park. "A miniature UWB planar monopole antenna with $5-\mathrm{GHz}$ bandrejection filter and the time-domain characteristics", IEEE Trans. Antennas Propag., vol. 54, no. 5, pp. 1453-1460, May 2006. https://doi.org/10.1109/TAP.2006.874354.

[6] Chin-Yu Huang, Wei-Chun Hsia, and Jieh-Sen Kuo. "Planar ultrawideband antenna with a band-notched characteristic", Microwave and Optical Technology Letters, 2005.

[7] Wen Jiang and Wenquan Che. "A Novel UWB Antenna with Dual Notched Bands for WiMAX and WLAN Applications", IEEE Antennas and Wireless Propagation Letters, VOL 11, 2012.

[8] Sung, Y. "UWB Monopole Antenna with Two Notched Bands Based on the Folded Stepped Impedance Resonator", IEEE Antennas and Wireless Propagation Letters, 2012. https://doi.org/10.1109/LAWP.2012.2199073.

[9] James R. Kelly, Peter S. Hall, and Peter Gardner. "Band-Notched UWB Antenna Incorporating a Microstrip Open-Loop Resonator", IEEE Transactions On Antennas and Propagation, Vol. 59, No. 8, August 2011 https://doi.org/10.1109/TAP.2011.2152326.

[10] Di Jiang, Yuehang $\mathrm{Xu}$, Ruimin $\mathrm{Xu}$ and Weigan Lin. "Compact dual-band-notched UWB planar monopole antenna with modified CSRR", Electronics Letters, 27th September 2012 Vol. 48 No. 20 https://doi.org/10.1049/el.2012.2489.

[11] xianglong liu, yingzeng yin, pingan liu, junhui wang, and bin $\mathrm{xu}$. "a cpw-fed dual band notched uwb antenna with a pair of bended dual1-shape parasitic branches", progress in electromagnetics research, vol. 136, 623.634, 2013

[12] fangfang fan, zehong yan, tianling zhang, and yue song. "ultrawideband planar monopole antenna with dual stopbands", microwave and optical technology letters / vol. 52, no. 1, january 2010.

[13] chen wang, ze-hong yan, bo li, and ping xu. "a dual band-notched uwb printed antenna with c-shaped and u-shaped slots", microwave and optical technology letters / vol. 54, no. 6, june 2012.

[14] Liu, Xianglong-L., Yingzeng-z. Yin and Jjunhui-H. Wang. "A compact dual band-notched UWB antenna with meandering slot and c-shape strips", microwave and optical technology letters / vol. 55, no. 11, November 2013.
[15] sanjeev kumar mishra, rajiv kumar gupta, avinash vaidya, and jayanta Mukherjee. "a compact dual-band fork-shaped monopole antenna for bluetooth and uwb applications", ieee antennas and wireless propagation letters, vol. 10, 2011

[16] Thomas, K.G., and M. Sreenivasan. "A simple ultrawideband planer rectangular printed antenna with band dispensation", IEEE transaction on antennas and propogation,2010.

[17] Chia-Ching Lin, Peng Jin, and Richard W. Ziolkowski. "Single, Dual and Tri-Band-Notched Ultrawideband (UWB) Antennas Using Capacitively Loaded Loop (CLL) Resonators", IEEE Transactions on Antennas and Propagation, VOL. 60, NO. 1, January 2012.

[18] Dang Trang Nguyen, Dong Hyun Lee, and Hyun Chang Park. "Very Compact Printed Triple Band-Notched UWB Antenna with Quarter-Wavelength Slots”, IEEE Antennas and Wireless Propagation Letters, VOL. 11, 2012.

[19] Debdeep Sarkar, Kumar Vaibhav Srivastava, and Kushmanda Saurav. "A Compact Microstrip-Fed Triple Band-Notched UWB Monopole Antenna", IEEE Antennas and Wireless Propagation Letters, VOL. 13, 2014.

[20] Mohammad Yazdi, and Nader Komjani. "Planar UWB Monopole antenna with dual band-notched characteristics for UWB applications", Microwave and Optical Technology Letters, Vol. 55, No. 2, February 2013. https://doi.org/10.1002/mop.27301. 